\title{
Factors influencing community participation in Community- Based Ecotourism in Padawan, Sarawak
}

\author{
Emily Rogos ${ }^{1 *}$, Kwang Sing Ngui ${ }^{2}$, and Teck Weng Jee ${ }^{3}$ \\ ${ }^{1}$ Department of Business, Swinburne University of Technology, Kuching, Sarawak \\ ${ }^{2,3}$ Faculty of Business, Design and Arts, Swinburne University of Technology, Kuching, Sarawak
}

\begin{abstract}
Community Based Ecotourism (CBE) has commonly practiced by the rural communities of Sarawak as poverty alleviation and local empowerment tool in conserving the natural resources in their livelihood. The community participation in the rural areas of Sarawak is essential in CBE sustainability. This study investigates the community participation in Community Based Ecotourism in Padawan, Sarawak. This study only applied for six selected villages in Kampung Sadir, Kampung Giam Danu, Kampung Annah Rais, Kampung Semadang and Kampung Benuk. These six villages are among the villages in Padawan that have ecotourism potential and availability. The application of the Motivation-Opportunity-Ability (MOA) used to analyse the categories of contributing factors towards the community participation in CBE. Their CBE activities included Tourist Centre/Guide, homestays, heritage festivals and outdoor activities. The method used to accomplish this study is snowball sampling techniques to recruit the participants to be involved in focus group interviews. For this study, the Village Chiefs were requested to select the suitable participants (ecotourism business providers, village committee and common villagers) to participate in focus group interview. Throughout the focus group interview, the participants were required to discuss on the issues or factors influencing their participation in $\mathrm{CBE}$. The findings reveal the factors that affecting motivation, opportunity and ability (MOA) of the community in involving in CBE.
\end{abstract}

\section{Introduction}

Malaysia is indeed blessed with various natural and cultural resources that make ecotourism a form of tourism that is highly beneficial, feasible, sustainable, and long term. Ecotourism has been proposed as a venture by which we can respond to the growing number of visitors seeking a pure environmental tourism experience, while reducing the negative effects and enhancing the benefits associated with tourism in the natural area (Boley \& Green, 2015). According to Bedford (2018), For ecotourists Borneo is a haven. With vast areas of rainforest, endemic species found elsewhere and an abundance of marine life, there's little wonder why Borneo's ecotourism thrives. Padawan is known as a sub-district of the city of Kuching, Sarawak. It has becoming more popular with its ecotourism experiences which mainly theme around the adventure, culture and nature (Dayak Wanderer 2018). Tourist attraction like hot spring, caves, jungle tracking, kayaking, and hiking are available in Padawan. CBE is known one of the option or platforms for rural communities to improve their standard of living by earning, provide job and gain local empowerment (Kim, Xie \& Cirella 2019). The essentiality of community participation in CBE is highly supported the Sustainability Development Goal (SDG) 2020 for Goal 1, 8, 11, and 17 .

\section{SDG 1: No Poverty}

Kim, Xie \& Cirella (2019) have stated that CBE has a high potential impact on the rural areas especially in developing countries. $\mathrm{CBE}$ is known as one of the poverty alleviations. It is a key for the community improve their living standards. CBE can alleviate poverty, diversify economic activity and increase indigenous goods and services demand and sales (Latip et al., 2018).

\section{SDG 8: Decent Work and Economic Growth}

Aligned with Kaur, Jawaid and Othman (2016), CBE also allowed the community to obtain decent work and economic growth by involving in ecotourism industry such as homestays, local handicraft and outdoor tourist guide. They also mentioned that the success of Homestays Programme performances increases in its quality through generating more income

\footnotetext{
*Corresponding Author: erogos@swinburne.edu.my
} 
and profits to the community. Latip et al. (2018) stated that the previous studies identified several positive economic impacts of tourism on destination communities, including increased family income and more opportunities for employment.

\section{SDG 11: Sustainable Cities and Communities}

The sustainable cities and communities can be achieved through CBE as it allows the community to empower each other in managing their resources. Kaur, Jawaid and Othman (2016) mentioned that CBE a powerful tool to empower the communities to develop their entrepreneurial, administrative, communication (interpersonal), and leadership skills when running homestay establishments. This involvement empowers the local community in earning money particularly in every aspect of tourism management. In addition, CBE can help the communities to preserve their culture, tradition and heritage. Regmi and Walter (2015) stated that the homestay operators take pride in their recognition as the stalwarts of local traditions through CBE. Not only do they maintain their culture and heritage as well as prepare the next generation to uphold their culture

\section{SDG 17: Partnership for the Goals}

The collaboration or partnership is known as one of the key principles in CBE in most of the developing countries. Stone (2015) has written about community-based ecotourism from a collaborative partnership perspective with the aim to as assess the perception of community-based ecotourism in terms of community involvement and empowerment. Accordance to this study, collaborations and partnerships between government, business, non-profit, funding and development agencies are increasingly being promoted as effective strategies to adopt a vision otherwise impossible if independent, and rural community entities work alone in CBE.

\subsection{Study Background}

According to the aim of this study, the phenomenon of CBE should be studied thoroughly. It is crucial to understand the definition of CBE, Community Participation and MOA and the relations between these three dimensions.

\subsubsection{Community Based Ecotourism (CBE)}

Ubidah et al. (2018) stated that tourism is the second-largest industry to contribute revenues to the state economy in Sarawak. Ecotourism is known as a concept of sustainable tourism in offering the abundance of natural and unique cultural resources. Ecotourism is based in rural communities' livelihood but mostly operated by outsiders, especially private tours. The rural communities started to feel that their resources have been manipulated by outsiders for their own profit. Therefore, CBE has been introduced to solve this problem. The difference of ecotourism and CBE is that CBE is a new form of tourism product that organizes or manages the major part of tourism management by local communities. CBE offers tourists the chance to learn about the community's way

\subsubsection{Community Participation}

The community participation is one of the main success factors in CBE. This means the higher the level of community participation the higher potential of success of CBE in that particular area. Community participation is a process of working together to the benefit of the local community. Community participation can create a sense of belonging, motivation and credibility among the members of the community. Based on study done by Kaur, Jawaid and Othman (2016), it has proven that the community participation has significant impact on CBE. The local communities are assured that they are fully responsible for all facets of their tourism management including from decision-making, planning, evaluation and management of their tourism. Hence, the effectiveness of CBE to the local communities over time needs to be enhanced. Communities must be fully empowered to manage tourism within their communities so that they can evolve independently in an integral part of $\mathrm{CBE}$.

\subsubsection{Motivation-Opportunity-Ability (MOA) Model}

The used of MOA helped to conceptualize a framework of understanding on the factors that influence community participation in CBE in the selected six villages in Padawan, Sarawak. The MOA model was previously used in the literature on tourism to explain the background to resident participation in information processing and decision making (Rasoolimanesh, Jaafar, Ahmad \& Barghi, 2017). According to Latip, Rasoolimanesh, Jaafar, Marzuki and Umar (2018), this model is useful for explaining the antecedents of community participation. MOA model implied to motivation to fulfill the need for a condition, an appropriate method and opportunity to participate in the process and the ability to continue. According to Rasoolimanesh, Jaafar, Ahmad \& Barghi (2017), In the MOA model, motivation implies any force that leads individuals to a set of goals or desired conditions and encourages them to engage and support the decisionmaking process. Opportunity refers to conditions such as political will, underlying social rules and the existence of 
appropriate channels that enable and facilitate residents ' participation in tourism activities and conservation programs. The ability refers to the ability of the community in handling the CBE by using their knowledge and skills. In this study, the factors such as self-interest and exposure might affect the motivation of the community, challenging infrastructure and limited facilities might limit the business opportunity for the community, and whether the community has enough ability to sustain their participation in CBE in utilizing their knowledge and skills.

\section{Methodology}

This is an exploratory qualitative research. This research is designed to be applied for six selected villages that located in Padawan District, Sarawak. These villages have been involved in CBE programme in many years but facing dropped in community participation. They are Kampung Sadir, Kampung Giam Danu, Kampung Annah Rais, Kampung Semadang and Kampung Benuk. This study aimed to explore the factors influencing the community participation in CBE in these sites according to various perspectives. The perspectives obtained from ecotourism business providers, village committee and common villagers. Hence, it is necessary for to collect the data of this study through focus group interviews to fulfil the limited timeframe.

This study employed a snowball sampling technique to recruit the participants. This sampling method includes a primary source of data appointing other potential data sets that will be able to participate in the study. It is purely based on referrals to engage the researcher to produce a sample. For this study, the Village Chief of every village has selected around seven to ten of the relevant participants for the focus group interviews if they were ecotourism business providers, village committee and common villagers of that village. Due to local common custom, only the Village Chiefs can select the suitable respondents for a focus group study and provides contacts to the researcher.

The outcome of the focus group interview is categorized according to MOA Model. The factors obtained will be compared among the villages after they were categorized under three-dimension, Motivation, Opportunity and ability regarding the respondents' perspectives on the community participation in CBE on their personal side as well as in their livelihood. Each Interview took about 30 minutes to one hour. The interview is conducted in Malay Language according to the comfortability of the respondents. The interviews have been recorded for the researcher to transcribe, translate and back translation. Then the data were analysed using thematic analysis.

\section{Results and Discussion}

\begin{tabular}{|l|l|r|r|r|r|r|r|}
\hline MOA & \multicolumn{1}{|c|}{ Village } & Sadir & Giam & Danu & $\begin{array}{c}\text { Annah } \\
\text { Rais }\end{array}$ & Semadang & Benuk \\
\hline \multirow{5}{*}{ Motivation } & Factors & & & & & \\
& Lack of interest & $\checkmark$ & & $\checkmark$ & $\checkmark$ & $\checkmark$ & $\checkmark$ \\
\hline & Lack of exposure & $\checkmark$ & & & $\checkmark$ & $\checkmark$ & $\checkmark$ \\
\hline & Inconsistent Income & & $\checkmark$ & & & $\checkmark$ & $\checkmark$ \\
\hline & Financial Constraints & $\checkmark$ & $\checkmark$ & $\checkmark$ & $\checkmark$ & $\checkmark$ & $\checkmark$ \\
\hline \multirow{5}{*}{ Opportunity } & Limited Facilities & $\checkmark$ & $\checkmark$ & $\checkmark$ & $\checkmark$ & $\checkmark$ & $\checkmark$ \\
\hline & Lack of Awareness & $\checkmark$ & $\checkmark$ & $\checkmark$ & $\checkmark$ & $\checkmark$ & $\checkmark$ \\
\hline & Inconsistent Tourist & $\checkmark$ & & & & $\checkmark$ & $\checkmark$ \\
\hline & $\begin{array}{l}\text { Challenging } \\
\text { Infrastructure }\end{array}$ & $\checkmark$ & & & $\checkmark$ & $\checkmark$ & \\
\hline \multirow{5}{*}{ Ability } & Lack of emplovment & $\checkmark$ & $\checkmark$ & $\checkmark$ & $\checkmark$ & & \\
\hline & Lack of Leadership & & $\checkmark$ & & $\checkmark$ & & $\checkmark$ \\
\hline & Skills limitation & $\checkmark$ & $\checkmark$ & $\checkmark$ & $\checkmark$ & $\checkmark$ & $\checkmark$ \\
\hline & $\begin{array}{l}\text { Lack of youngsters } \\
\text { support }\end{array}$ & & $\checkmark$ & & & $\checkmark$ & $\checkmark$ \\
\hline \multicolumn{2}{|c|}{ Total of Factors } & 9 & 8 & 6 & 9 & 10 & 10 \\
\hline
\end{tabular}

Overall, there are 12 factors that were identified in this research which are lack of interest, lack of exposure, inconsistent income, financial constraints, limited facilities, lack of awareness, inconsistent tourist, challenging infrastructure, lack of employment, lack of leadership, skills limitation, and lack of youngsters' support. 
The table 1 above shows the factors that affects CP according to the villages. Based on the table above, Kampung Semadang and Kampung Benuk recorded the highest factors (10) that affects their CP. The second highest factor (9) was recorded by Kampung Sadir and Kampung Annah Rais. While Kampung Giam recorded 8 factors that affects their CP. Kampung Danu recorded the least number of factors (6) that affects their CP.

\subsection{Motivation}

Motivation is perceived as the driving force behind a person's decision-making process as it can affect the intensity and direction of behaviour. In this section, there are 4 factors that were identified under motivation which are lack of interest, lack of exposure, inconsistent income, and financial constraints.

\subsubsection{Lack of interest}

This factor was shown by all village except for Kampung Giam. There are various reasons found behind having lack of interest for other villages. For example, the people in Kampung Sadir and Kampung Seamadang found that due to financial limitation and poor accessibility to their village, the local community are less interested to participate in ecotourism activities. Furthermore, the poor transportation system to their village will hinder the tourist to travel to their village therefore, the local community in Kampung Sadir felt that this business does not have bright potential in their village.

The local community in Kampung Annah Rais on the other hand showed genuine interest to be involved in this sector as they are aware of the positive reasons behind involvement in ecotourism. Majority of the villagers are aware the existence of resources and the cultural attraction that they have. However, the minority of the local community expressed their disinterest in participation in ecotourism due to having other commitment and lack of self-confidence. This reason was found to be the same with the local community in Kampung Benuk as well.

\subsubsection{Lack of exposure}

Lack of exposure was found to be a factor that affects CP in Kampung Sadir, Kampung Annah Rais, Kampung Semadang, and Kampung Benuk. This factor could possibly be triggered from the previous factor discussed which is lack of interest. The local community in Kampung Annah Rais and Kampung Benuk has highlighted that they lack interest of interest in $\mathrm{CP}$ as they do not have confidence to participate in CP due to lack of exposure.

Lack of exposure can be tackled by a simple solution which is obtaining $3^{\text {rd }}$ parties assistance to aid the local community by providing them with necessary training and exposure to ecotourism. This issue was more evident when a respondent exposed that they do not have any awareness of the ecotourism activities that are available in the village such as in Kampung Semadang and Kampung Sadir.

\subsubsection{Inconsistent income}

Inconsistent income was found to be affecting only 3 villages which are Kampung Giam, Kampung Semadang, and Kampung Benuk. This factor also was found to trigger the lack of interest among the local communities. Kampung Semadang and Kampung Benuk has inconsistent tourist arrival hence it leads to having inconsistent income. This is since there is less ecotourism provider among the local community as they lack interest to be involved in ecotourism.

Furthermore, Kampung Semadang has highlighted that lack of transportation accessibility to their village as a major issue. Therefore, there are less tourist arrival into their village ence causes an inconsistency to their income. This in turns causes them to be less interested to be in the ecotourism business.

Kampung Giam on the other hand has observed the inconsistency in the tourist arrival to their village therefore the local community there prefer to work outside their village or focussing more towards agriculture. Apart from that, the local community are not willing to take risk of facing inconsistent income issue in their business as the local community there prefer to have a steady income.

\subsubsection{Financial Constraints}

Financial constraint has been proven in this research to be the main the issue for all the 6 villages in this study to affect participation of the local communities in ecotourism activities. All villages have expressed the same reason behind being not interested to participate due to financial limitation.

For instance, in Kampung Benuk, the local communities felt that if financial assistance was given to them, there are possibilities where the local communities might be interested into ecotourism business. Furthermore, the local communities in Kampung Benuk highlighted that there was an effort to request for funding from some government organisation, unfortunately they were not able to obtain the funds. Kampung Semadang on the other hand was found to be fortunate to obtain the fund. 
Similar unfortunate situation happened in Kampung Danu. It was found that the homestays in Kampung Danu requires some upgrade in terms of the condition of the homestays. The local community took the initiative to seek for external funds, however, until the date of this research took place, there is no outcomes of their funding application.

\subsection{Opportunity}

Within the field of tourism, opportunity is defined as circumstances which facilitates the public involvement in the participation process. Opportunity occurs when planners adopt a participatory approach which provides a supportive framework for community participation. The factors found to affect participation in this section are limited facilities, lack of awareness, inconsistent tourist, and challenging infrastructure.

\subsubsection{Limited facilities}

Similar to financial constraints, limited facilities were found to be another serious factor that affects all the 6 villages in this study. The facilities in this study refers to lack of commercial centre or convenient stores for the tourist. For instance, in Kampung Annah Rais, the local community voiced out that their village lacks supermarket. Currently, the local community on has small groceries shop however, it does not offer a wide range of products in there.

Apart from that, some village highlighted lack of internet centre in their village. This is closely linked to challenging infrastructure as some village has poor internet connection. This issue was seen in all the villages where they highlighted the issue of poor internet service. However, the local community in Kampung Annah Rais suggested that having an internet centre could be beneficial to the local community as that could help them to promote their activities more.

Furthermore, poor homestay condition also affected the CP of the local communities especially in Kampung Danu. It was understood, that the funding's that Kampung Danu obtains are from their ecotourism business are not enough to sustain the existing homestays. The financial conditions and the effect have been explained in the section 3.1.4 above.

Kampung Sadir on the other hand lacks facilties from transportation services point of view. One of the respondents from Kampung Sadir mentioned that they loose tourist just because they could not provide transportation services to their potential customer.

\subsubsection{Lack of awareness}

Lack of awareness were also one of the most serious issue for all the 6 villages in Padawan. The local communities of all the villages were found to be not realising the opportunities that they have which could potentially be a tourist hotspot in their local village hence, lack of awareness was considered as a serious factor.

Some villages felt that ecotourism is not their main objective therefore, they do not focus on the opportunities that they have. For example, in Kampung Giam, the local community's main resource is agriculture, therefore, the local communities there felt that ecotourism will not benefit them as their agriculture resource is enough to sustain their lifestyle.

On a positive side, some of the local communities are aware of the potential that they have, but these group does not wish to take the chance as there are other factors that affects their decision. For example, in Kampung Benuk, the community are aware of the potential that they have, however, factors such as financial constraints hinders them from participating in these activities.

\subsubsection{Inconsistent tourist}

Inconsistent tourist has affected 3 villages which are Kampung Sadir, Kampung Semadang, and Kampung Benuk. In this study, inconsistent tourist refers to the inconsistency of tourist arrival in these 3 villages. Inconsistent tourist arrival may affect the financial condition of the villages as the villages will loose their income if they rely on this sector for income generation.

In Kampung Sadir, the tourist arrival highly depends on season. For example, on a typical day less tourist visits the village, however, during Gawai festival, more tourist arrives in their village to experience the local festival.

Kampung Semadang on the other hand lacks tourist mainly due to lack of activities that are offered by ecotourism service providers. On a common ground with Kampung Sadir, tourists are more seen in Kampung Semadang during fishing festival. On a typical day, tourist only comes to visit the herbs garden available there. It was observed that Kampung Semadang does have a wide range of activities to offered, however, the local communities there decided not to take this opportunity as it does not contribute much to their earning.

\subsubsection{Challenging infrastructure}

Challenging infrastructure is a typical issue in most of the villages in Malaysia. This includes the villages in Padawan as well. In this study, only 3 villages highlighted this issue which are Kampung Sadir, Kampung Annah Rais, and Kampung Semadang. 
The first issue in infrastructure found was poor internet connection. The local communities felt that these issues severely affect their ecotourism business. The community in Kampung Sadir believes that with the existence of better internet connection, they would be able to promote their local events or even their ecotourism business. This issue is predicted to hinder the communication between the ecotourism providers and the potential tourist who wish to reach Kampung Sadir. Similar issue was found to occur in Kampung Annah Rais.

As for Kampung Semadang, the local communities there faces infrastructure issue related to proper paved road which could ease the transport system accessibility to their village. This issue was found to affect one of the kayaking activity service providers where they found it difficult for them to transport their kayaks to the river in a safe manner.

\subsection{Abilities}

Ability is seen as a complex entity which includes a combination of factors such as awareness, experience, knowledge, skills, accessibility to information and financial resources. According to the concept of MOA model, even though a community member has the right to participate and is motivated to seek out the opportunity, they may lack the ability to do so. The factors identified under this section are lack of employment, lack of leadership, skills limitation, and lack of youngsters support.

\subsubsection{Lack of employment}

Lack of employment is associated with lack of manpower or lack of labour. These issues occurred in Kampung Giam, Kampung Sadir, Kampung Annah Rais, and Kampung Danu. It is a well-known fact that lack of manpower could affect a business severely therefore, this issue should not be taken lightly. The villages that are affected by this factor has shown high motivation to be involved in ecotourism as the local communities are aware of the opportunities that they have, however, due to manpower issue, they are unable to involve in ecotourism activities.

Among all the villages that are affected by this issue, Kampung Giam is the most affected village by this issue. As mentioned before, the local community in Kampung Giam are more focussed into agriculture as they felt that ecotourism business is not beneficial to the community in that village. Therefore, majority of the villagers prefer to not be involved in ecotourism.

\subsubsection{Lack of leadership}

Leadership is the most important factor for a village to progress forward in any sector. Lack of leadership could create a severe negative impact in any community especially in local communities in Padawan rural area. In this study, Kampung Giam, Kampung Annah Rais, and Kampung Benuk was found to be affected by lack of leadership issue. Kampung Annah Rais, despite lacking leadership issue, the ecotourism business there runs on individual initiative issue.

Kampung Benuk faces an issue related to leadership due to the lack of management skills that are available among their community leaders. It is believed this is due to the lack of awareness that they have related to ecotourism business. Skill limitation was found to be another serious factor among all the 6 villages in this study. Skills limitation in this study is linked to skills related to management of the local community to operate their ecotourism business. Majority of the communities voiced out that they lack homestay management skills. While some village such as Kampung Annah Rais did tackle this issue by joining homestay management course, other village are reported to not join this course as they were unable to receive information related to homestay management course that took place around their area.

The local communities in Kampung Benuk highlighted few skills limitations issue such as poor writing skills which affects their communication skills with potential tourist. Apart from that poor verbal communication skills is also an issue the local community in Kampung Benuk which affects their verbal information delivery when the tourist are brought around the village.

\subsubsection{Lack of younger generation involvement}

It is predicted in the future that young generations will take over these ecotourism businesses. Therefore, it is essential for the young generation to be involved in this business to ensure they have adequate experience in ecotourism sector. Unfortunately, the reality is there are 3 villages such as Kampung Giam, Kampung Semadang, and Kampung Benuk lacks young generations involvement.

A respondent in Kampung Benuk views this issue as a serious issue as they find it tough to get the younger local communities to be involved as they are being more antisocial. This is probably due to the mindset that that the young local communities have, or their working style does not suit this sector. The local communities in Kampung Benuk believes that involving the young local communities could lead to more innovative ideas which can be used to enhance the ecotourism sector.

The issue with young generation involvement in Kampung Giam is different from Kampung Benuk. In Kampung Giam, the younger generations believe that ecotourism business is not profitable to them therefore, the young generations prefers to work outside as the income offered outside are much better than ecotourism business in their village. 


\section{Conclusion and Recommendation}

This study was performed to investigate the community participation in Community Based Ecotourism (CBE) in Padawan, Sarawak. The study was conducted in six selected villages which Kampung Sadir, Kampung Giam Danu, Kampung Annah Rais, Kampung Semadang and Kampung Benuk. These six villages are among the villages in Padawan that have ecotourism potential and availability. The application of the Motivation-Opportunity-Ability (MOA) used to analyse the categories of contributing factors that affects the CBE. 12 factors were identified through this study which are lack of interest, lack of exposure, inconsistent income, and financial constraints, limited facilities, lack of awareness, inconsistent tourist, and challenging infrastructure, lack of employment, lack of leadership, skills limitation, and lack of youngster's support.

Considering these factors, some recommendations has been suggested in order to aid these villages to improve their ecotourism sector. The first recommendation is increase awareness in the field of CBE. This will potentially create interest and therefore, will provide exposure to the local communities to perform well in ecotourism sector.

Second recommendation is to improve marketing strategies and partnering with external bodies as there is an issue of inconsistent income. This will result in more tourist incoming hence eliminating the inconsistent tourist arrival.

As most of the villages are affected by financial constraint, the local communities are encouraged to obtain tourism grant weather from non-government organisations or government organisation. Apart from that, the local communities could collaborate with the travel agencies to promote their village hence, this creates potential for more tourist coming to the village. This collaboration will also improve the facilties, and the infrastructure of the village.

Some villages highlighted that they lack manpower. This could be solved by educating the villagers the importance of $\mathrm{CBE}$ and ecotourism. Besides, benefits should be provided to the villagers who are involved in $\mathrm{CBE}$. This could attract more local communities to be involved in the CBE related activities. Creating a CBE community also could help to tackle this issue, hence, improves the leadership of the community to spearhead the ecotourism related activities in the village.

Finally, external parties should grab the opportunity to provide training programs for local communities related to ecotourism management. This will help the local community to improve their skills in managing ecotourism. The training session also should target younger generations to grab their interest in ecotourism

\section{References}

1. Bedford, S. (2018). The 10 Best Ecotourism Experiences in Borneo. Retrieved 25 February 2020, from https://theculturetrip.com/asia/malaysia/articles/the-10-best-ecotourism-experiences-in- borneo/

2. Boley, B., \& Green, G. (2015). Ecotourism and natural resource conservation: the 'potential' for asustainable symbiotic relationship. Journal Of Ecotourism, 15(1), 36-50. doi:10.1080/14724049.2015.1094080

3. Kaur, P., Jawaid. A., \& Othman, N (2016). The Impact of Community Based Tourism On Community Development in Sarawak, Journal of Borneo Kalimantan, Institute of Borneo Studies (pp. 15-26). UNIMAS.

4. Kim, M., Xie, Y., \& Cirella, G. (2019). Sustainable Transformative Economy: Community-Based Ecotourism. Sustainability, 11(18), 4977. doi: 10.3390/su11184977

5. Latip, N., Rasoolimanesh, S., Jaafar, M., Marzuki, A., \& Umar, M. (2018). Indigenous participation in conservation and tourism development: A case of native people of Sabah, Malaysia. International Journal Of Tourism Research, 20(3), 400-409. doi: 10.1002/jtr.2191

6. Rasoolimanesh, S., Jaafar, M., Ahmad, A., \& Barghi, R. (2017). Community participation in World Heritage Site conservation and tourism development. Tourism Management, 58, 142-153. doi: 10.1016/j.tourman.2016.10.016

7. Regmi, K., \& Walter, P. (2016). Conceptualising host learning in community-based ecotourism homestays. Journal Of Ecotourism, 15(1), 51-63. doi: 10.1080/14724049.2015.1118108

8. Stone, M. (2015). Community-based ecotourism: a collaborative partnerships perspective. Journal Of Ecotourism, 14(2-3), 166-184. doi: 10.1080/14724049.2015.1023309

9. Ubaidillah, N. Z., Ab-Rahim, R., Jul, S., Edman, A. B. N. A. S., \& Hamdan, R. (2018). Analysing the Local Communities' Perception on the Economic and Environmental Factors of Ecotourism in Tagang System Framework-The Case of Semedang Village, Sarawak, Malaysia. International Journal of Academic Research in Business and Social Sciences, 8(11), 1056-1068.

10. Wanderer, V. (2018). Things to do in Padawan, Kuching. Retrieved 25 February 2020, from https://dayakwanderer.com/2018/10/26/things-to-do-in-padawan-kuching-sarawak/ 